\title{
CORRECTION
}

\section{Correction to: Determination of interactions of ferrihydrite-humic acid-Pb (II) system}

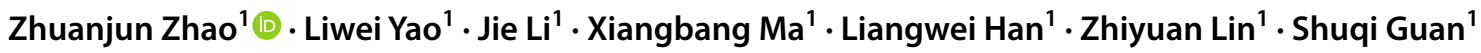

Published online: 22 November 2021

(c) Springer-Verlag GmbH Germany, part of Springer Nature 2021

\section{Correction to: Environmental Science and Pollution Research}

https://doi.org/10.1007/s11356-021-17258-z

The equal contribution statement for Zhuanjun Zhao and Liwei Yao is missing and it is inserted in the revised proof. Zhuanjun Zhao and Liwei Yao are co-first author.

The Original article has been corrected.

Publisher's note Springer Nature remains neutral with regard to jurisdictional claims in published maps and institutional affiliations.

The original article can be found online at https://doi.org/10.1007/ s11356-021-17258-z.

Zhuanjun Zhao

zhj_zhao@1zu.edu.cn

$\triangle \mathrm{Jie} \mathrm{Li}$

jieli19@1zu.edu.cn

1 Key Laboratory of Western China's Environmental Systems (Ministry of Education) and Key Laboratory for Environmental Pollution Prediction and Control, Gansu Province, College of Earth and Environmental Sciences, Lanzhou University, Lanzhou 730000, People's Republic of China 